\title{
ANÁLISE DO PERFIL EMPREENDEDOR DOS ALUNOS/EGRESSOS DO CURSO DE ADMINISTRAÇÃO DA UPE- CAMPUS SALGUEIRO/PE
}

\author{
Danilo de Queiroz Lima (UPE - Campus Salgueiro) dan_ilo_s.t@hotmail.com \\ Tiago Silveira Machado (UPE - Campus Salgueiro) tiago.machado@upe.br \\ Wanderberg Alves Brandão (UPE - Campus Salgueiro) wanderberg.brandao@upe.br
}

\section{Resumo}

No decorrer dos anos, o empreendedorismo vem crescendo no Brasil, consequentemente atraindo a atenção dos estudiosos, para compreender como esse grupo age na economia. Este artigo teve como objetivo analisar o perfil empreendedor dos alunos/egressos do curso de administração da UPE campus Salgueiro. Os conceitos teóricos abordados contemplam o tema de empreendedorismo e o perfil do empreendedor, dando ênfase na temática principal da pesquisa, que são os alunos e egressos da instituição. Metodologicamente, foi utilizada a abordagem quantitativa, usando como ferramenta de coleta de dados um questionário composto por 10 questões objetivas e uma delas em escala Likert com 05 afirmativas, aplicado por meio do Google Forms, obtendo 100 respostas, onde afirma que o público em questão são cautelosos, investem pouco, e tendem a ser empreendedores por oportunidade, tendo uma certa curiosidade acerca do tema, porém não tem o incentivo necessário da universidade quando se trata empreender, buscando outras áreas da administração para se profissionalizarem.

Palavras-Chaves: Empreendedorismo. Mercado de trabalho. Necessidade. Inovação. Oportunidade.

\section{Introdução}

Em um mundo cada vez mais competitivo, há muitas pessoas que não estão satisfeitas com seus empregos, tal situação gerada muitas vezes pelo estresse no trabalho, pressão e salários não justos. Essas pessoas buscam em meio a essas frustrações uma oportunidade de aflorar seu espírito de líder, surgindo assim, o desejo de montar seu próprio negócio, e gerir sua própria equipe.

Empreendedorismo é quando se tem uma iniciativa própria na elaboração de um negócio, bem ou serviço, não necessariamente sendo em um ambiente físico, mas que proporcione ao seu idealizador um meio que se tenha para se trabalhar e gerar renda com aquilo que foi estabelecido por si mesmo, podendo ser o início de grandes negócios, se seguido com dedicação.

Hashimoto (2016), diz que os negócios tendem a continuar pequenos não pela natureza dos negócios e sim por causa do seu idealizador. Ser empreendedor não é apenas montar seu próprio negócio, é enxergar oportunidades naquilo que ninguém viu, podendo ser um produto/serviço novo, ou um já existente que estava entrando em declínio, que com uma 
injeção de inovação e boa gestão, saia dessa zona crítica e volte ao ápice, passando de uma empresa detratora, para uma promotora, tendo o poder de transformar qualquer pequena empresa em um grande negócio.

De acordo Costa (2017), os empreendedores por necessidade, são pessoas que estão passando por alguma dificuldade financeira, perderam emprego, ou não estão conseguindo ingressar/recolocar-se no mercado de trabalho, e veem a abertura de um negócio como sua única saída, geralmente não tem experiência no ramo, tomando medidas desesperadoras para resolverem seus problemas, enfrentando mais dificuldade para o sucesso da sua organização.

Segundo Mallmann (2017), O empreendedor por oportunidade, é um excelente observador, ele é capaz de detectar facilmente as necessidades e demandas do consumidor. Em uma simples análise, esse indivíduo tem claro em sua mente, qual produto ou serviço deve ser implementado no mercado. Assim, definiu-se o seguinte objetivo de analisar o perfil empreendedor dos alunos/ egressos do curso de administração da UPE Campus Salgueiro.

\section{Fundamentação Teórica}

\subsection{Empreendedorismo}

Os conceitos e teorias a respeito do empreendedorismo são amplos, para Nuccio e Wollheim (2016), Empreendedorismo, é como um vírus, que pode ficar estacionado no organismo durante anos, ou até mesmo podendo permanecer a vida inteira, e nunca despertar. Não há uma lógica ou uma hora certa, simplesmente acontece, independente de idade, ou classe social; cada indivíduo tem seu momento, pode ser jovem como Jan Koum que aos 37 anos fundou o WhatsApp, ou aos 60 anos, idade que tinha Roberto Marinho quando criou a Rede Globo, uma das maiores redes de telecomunicação do mundo.

Segundo Chiavenato (2012), os empreendedores são peça chave no ramo dos negócios, por proporcionar geração de empregos, implementar o novo, e disseminar o crescimento da economia de uma determinada região. É através dessas mentes inovadoras, que dão a oportunidade de pessoas ingressem no mercado de trabalho; aumenta a competitividade, maximizando as opções de compras dos consumidores, aquecendo a economia, conduzindo o crescimento da cidade/estado e/ou país. 
Custódio (2011) afirma que suas atitudes empreendedoras não devem focar apenas em lucros, empresas e objetivos monetários, e sim no seu capital humano, na gestão de pessoas, pensar na saúde de seus colaboradores, pois são essas atitudes que são fundamentas para o sucesso ou fracasso da empresa.

Esses profissionais são pessoas inovadoras, criativas e visionárias, que pensam a frente do seu tempo, buscando trazer para a atualidade, algo que necessitaremos no futuro, sem necessariamente esperar que a situação aperte para encontrar a solução, buscam aprimoramentos, de um bem/produto já existente, à criação de um novo que irá suprir nossas necessidades que talvez hoje não precisaremos, mas que amanhã seja fundamental para nossa sobrevivência.

\subsection{Inovação e Riscos}

Na visão de muitos, montar seu próprio negócios é algo simples, mas para Peter Drucker (1970 apud Chiavenato 2012 p.8) "o empreendedorismo se refere a assumir riscos" o que significa que a pessoa que deseja empreender, tem que está disposta para o mesmo, principalmente no Brasil, onde a burocracia é grande, impostos abusivos, e poucos incentivos governamentais, o que dificulta muito o empreendedor que está no início de carreira, se comparado a países desenvolvidos.

Chér (2016) complementa dizendo que empresário é aquele que tem empresa como propriedade em meio aos negócios; já o empreendedor é um conjunto de atitudes, independente se o indivíduo seja ou não o dono da empresa, podendo assim, agir como empreendedor sem necessariamente ser o proprietário.

De acordo com Oda (2017), para inovar nos negócios é necessário buscar capacitações, desenvolver criatividade e aperfeiçoar diferentes habilidades, é necessário está em constante movimento, sempre em busca de conhecimento, tendências, ter um olhar visionário, fazer uma pesquisa de mercado, para ver se um determinado negócio ou produto terá saída, ter um bom marketing, acompanhar a tecnologia, que está cada vez mais presente no nosso cotidiano.

Para Maximiano (2012 p. 326), “a pessoa que assume o risco de começar uma empresa é um empreendedor", a partir do momento que se inicia uma empresa, já está sujeito ao risco, que quanto maior, pode ser o retorno, ou o fracasso, portanto para ser empreendedor tem que estar ciente de todas as suas despesas: aluguéis, funcionários, instalações, impostos e todas 
obrigações necessárias para encarar um negócio, é ter uma visão ampla de todas as barreiras que serão enfrentadas nessa etapa, fazendo um planejamento cauteloso acerca do empreendimento.

Cerbasi (2016) informa que um dos maiores erros dos empreendedores é começar uma nova empresa um plano de negócios que leve em consideração diversos pontos importantes para o sucesso de uma organização como: riscos, retorno, lucro, investimento e ponto de equilíbrio; falhando inúmeras vezes em gestão de pessoas, esquecendo de investir no capital humano, peça que irá trazer todos esses resultados.

Muitas empresas no Brasil e no mundo fecham as portas, por não inovar, juntando com a ausência de estudo acerca do empreendimento, e oscilações que o mercado enfrenta, chegando a ter o temido prejuízo financeiro, por conta disso é de suma importância ter os riscos calculados para não ter frustrações futuras, e até mesmo a falência dos negócios, enfatizando a importância de empreender por oportunidade e não por necessidade.

\subsection{Empreendedorismo: oportunidade e necessidade}

A busca para empreender é constante, de acordo com Vale, Corrêa e Reis (2014), As pessoas são levadas ao empreendedorismo por dois motivos, são eles: oportunidade e necessidade; considera-se o primeiro aquele que abre uma empresa motivado pela identificação pelos negócios, onde já tem habilidade e familiaridade com o que vem a assumir; já o segundo, abre uma empresa pressionado por circunstâncias negativas, como a falta de emprego, sendo a única saída para se recoloca-se no mercado de trabalho.

Para Bona (2019), os empreendedores por necessidades são moldados mais pela situação econômica do país e tendem a diminuir quanto maior a oferta de emprego, isso significa que quando a geração de emprego é maior, a demanda de empreendedores por necessidade cai, sendo assim, quando há alta no desemprego, esse percentual de empreendedor por necessidade aumenta.

Mendes (2017), diz que o verdadeiro empreendedor não empreende por necessidade e sim por oportunidade, para ele sua única saída é vencer, e a necessidade só é uma barreira a ser vencida pela garra empreendedora; são obstáculos que servem como um pontapé inicial, para assumir riscos, começar seu próprio negócio, se dispor a implantar o novo, e ser o diferencial no mercado, transformando essa necessidade inicial em oportunidade para geração de auto 
emprego, ou dependendo do porte da empresa a multiplicação do mesmo, dando assim a chance de outras pessoas terem um espaço no mercado de trabalho.

A pesquisa GEM, o maior estudo sobre empreendedores do mundo Global Entrepreneurship Monitor (2018), afirma que 38\% da população adulta brasileira entre 18 a 64 anos são empreendedoras, a cada 5 brasileiros 2 são empreendedores e que no Brasil para cada empreendedor por necessidade há 1,6 empreendedor por oportunidade. A pesquisa caracterizando os empreendedores em 2 fases: iniciais e estabelecidos.

A pesquisa mostra que em 2018, 61,8\% dos empreendedores iniciais são por oportunidade, e $37,5 \%$ por necessidade, dados bastante positivos, sendo para cada por necessidade 1,6 são por oportunidade, um reflexo positivo para nossa economia, que cresceu 3 pontos percentuais do ano de 2015 (ápice da crise) para 2018. Isso mostra que o Brasileiro está cada vez mais consciente ao abrir um negócio, e gerando mais empregos.

O GEM (2018), mostra também que uma forte característica desses empreendedores é o auto emprego, mais de $80 \%$ dos empreendedores iniciais não tem empregados, ou seja trabalham sozinhos e $6 \%$ tem dois ou mais empregados, isso resulta em um número de 6,5 milhões postos de trabalhos, o que faz aquecer a economia, gerando prosperidade para o país.

Os números de empreendedores por oportunidade são bastante positivos para o país, mostrando que os brasileiros estão mais conscientes na hora de abrir seu negócio; considerando o aspecto econômico, também deve frisar os empreendedores por necessidade, aqueles que não conseguiram espaço no mercado, mas teve a atitude e determinação para ser dono do seu próprio negócio, fortalecendo ainda mais a economia da sua região.

\section{Metodologia}

De acordo com Vergara (2015) os tipos de pesquisa são determinados por dois critérios básicos: quanto aos fins e quanto aos meios. Quanto aos fins a pesquisa é considerada descritiva, que estudou as características de um grupo de pessoas, que no caso serão os egressos de administração, não havendo a interferência do pesquisador, e nem interferindo nos resultados, apenas apresentá-los.

Também caracterizada como exploratória que teve como objetivo mostrar uma familiaridade maior com o problema, tornando-o mais explícito ou construir hipótese (GIL 2002). Quanto 
aos meios, a pesquisa foi de campo, confrontando a teoria com a prática, buscando informações e conhecimento, verificando os fatos como eles se manifestam, afim de adquirir através de questionários aplicados, os dados específicos para a análise da população estudada e da relação que o empreendedorismo tem sobre esse grupo.

Em relação a coleta de dados, foi utilizado como instrumento o questionário, que é um dos mais usados para o levantamento de informação, o mesmo não estabelece uma quantidade de questões, porém aconselha-se que não seja muito exaustivo, para que o pesquisado consiga respondê-las com tranquilidade.

O questionário foi criado com questões que respondessem aos objetivos da pesquisa, de autoria do pesquisador, composto por perguntas fechadas, que são aquelas questões com respostas fixas, cabendo ao pesquisado responder dentre as quais, ele mais se identifica, sendo elas dicotômicas, composta por duas alternativas opostas (sim/não) e perguntas com resposta de múltipla escolha, onde o pesquisador tem várias opções que possa escolher e ser assinalada (BARROS; LEHFELD, 2007). Também foram utilizadas em algumas questões a escala Likert, composta com 05 níveis, que visa especificar o grau de concordância de uma afirmação.

Após ser aplicado, o questionário, obteve-se 100 respostas, com um pré-teste com 5 pessoas, onde foram apontados alguns indicadores a serem mudados, sua versão final resultou em um quantitativo de informações que serviu de auxílio para a análise, através de estatística descritiva com a elaboração de gráficos e tabelas, extraindo os dados obtidos do questionário, onde consideram as respostas que mais se destacaram.

A pesquisa foi desenvolvida na Universidade de Pernambuco (UPE), Campus localizado na Cidade de Salgueiro no nordeste brasileiro, sertão central do estado de Pernambuco a $513 \mathrm{~km}$ da capital Recife, com o PIB per capita de 13.070,53 e população de 56.629 habitantes segundo o último censo do IBGE (2018).

A UPE Campus Salgueiro é uma universidade pública com dois cursos superiores, Logística e Administração, esse último foi o escolhido como ambiente pelo pesquisador, por ser uma das áreas que mais se identificam com o empreendedorismo, e graduação seguida pelo próprio. $\mathrm{O}$ público alvo são os alunos e egressos de Administração, estudantes e os últimos estudantes a colarem grau do Campus em questão, no mês de março e agosto de 2019, sendo 40 egressos, 
164 matriculados e 15 desblocados, um universo de 219 pessoas, e uma amostra com 100 pessoas, $45,66 \%$ do universo, sendo um quantitativo bastante representativo.

\section{Resultados}

Analisando o perfil dos entrevistados, a Tabela 1 mostra que 53\% do gênero feminino e $47 \%$ do gênero masculino. Esses dados revelam que a população é homogênea, mas apresentou um percentual maior para o público feminino.

Quanto a idade, a maioria estão concentradas na faixa etária de 21 a 25 anos (80\%), entre 26 e 30 anos (12\%), entre 31 e 35 anos (5\%), entre 36 e 40 anos (2\%), acima de 41 anos apenas (1\%). Os dados revelam que a amostra estudada é majoritariamente jovem, pois $92 \%$ dos pesquisados possuem menos de 30 anos. Os resultados encontrados até o momento são vistos como coerentes, uma vez que o público vinculado do curso normalmente está nesta faixa etária.

Quanto ao vínculo atual com a UPE, 30\% dos respondentes são egressos do ano de 2018, 29\% estão cursando o $8^{\circ}$ período, $9 \%$ do $2^{\circ}$ período, $11 \%$ são estudantes do $4^{\circ}$ período, $11 \%$ alunos do $6^{\circ}$ período, e $10 \%$ desblocados. Combinando os dados relacionados aos estudantes do $8^{\circ}$ período, desblocados e egressos representam $69 \%$ dos entrevistados. Esse público é bastante representativo, pois se tratam de estudantes que já cursaram todas ou a maioria das disciplinas. Quando se trata de renda mensal dos pesquisados, 46\% ganham até 1.000,00 mensais; $33 \%$ de $1.001,00$ a 2.000,00; $21 \%$ a partir de $\mathrm{R} \$ 2.001,00$.

Tabela 1 - Perfil dos entrevistados

\begin{tabular}{|c|c|c|c|c|c|c|}
\hline \multicolumn{2}{|c|}{ Sexo } & \multicolumn{5}{|c|}{ Escolaridade } \\
\hline Masculino & $47 \%$ & \multicolumn{2}{|c|}{ Até R \$ $1.000,00$} & $46 \%$ & $\mathrm{R} \$ 3.001,00$ a $4.000,00$ & $6 \%$ \\
\hline \multirow[t]{2}{*}{ Feminino } & \multirow[t]{2}{*}{$53 \%$} & \multicolumn{2}{|c|}{$\mathrm{R} \$ 1.001,00$ a $2.000,00$} & $33 \%$ & $\mathrm{R} \$ 4.001,00$ a $5.000,00$ & $2 \%$ \\
\hline & & \multicolumn{2}{|c|}{$\mathrm{R} \$ 2.001,00$ a $3.000,00$} & $9 \%$ & Superior a $\mathrm{R} \$ 5.001,00$ & $4 \%$ \\
\hline \multicolumn{3}{|c|}{ Renda familiar } & \multicolumn{4}{|c|}{ Faixa etária } \\
\hline \multicolumn{2}{|l|}{$2^{\circ}$ Período } & $9 \%$ & \multicolumn{3}{|c|}{ Entre 21 e 25 anos } & $80 \%$ \\
\hline \multicolumn{2}{|l|}{$4^{\circ}$ Período } & $11 \%$ & \multicolumn{3}{|c|}{ Entre 26 e 30 anos } & $12 \%$ \\
\hline \multicolumn{2}{|l|}{$6^{\circ}$ Período } & $11 \%$ & \multicolumn{3}{|c|}{ Entre 31 e 35 anos } & $5 \%$ \\
\hline \multicolumn{2}{|l|}{$8^{\circ}$ Período } & $29 \%$ & \multicolumn{3}{|c|}{ Entre 36 e 40 anos } & $2 \%$ \\
\hline \multicolumn{2}{|l|}{ Desblocado } & $10 \%$ & \multirow{2}{*}{\multicolumn{3}{|c|}{ A partir de 41 anos }} & $1 \%$ \\
\hline Egresso (Formado) & & $30 \%$ & & & & \\
\hline
\end{tabular}

Fonte: Elaborado pelos autores

Quando se trata das expectativas quanto ao curso, os egressos/alunos estão bastante divididos, $40 \%$ deles almejam passar em concurso público em busca de estabilidade financeira, 29\% pretendem abrir negócio, essa parcela visa o empreendedorismo para suas vidas profissionais, 
$17 \%$ pretendem trabalhar na iniciativa privada, por se um meio mais fácil de se adentrar no mercado de trabalho, e 14\% querem adentrar na carreira acadêmica, e se tornarem docentes.

A Tabela 2 revela que o grau de interesse dos entrevistados classifica-se como razoavelmente alto, quanto ao interesse $29 \%$ total, $25 \%$ bastante e $23 \%$ razoável. De modo combinado, $77 \%$ apresenta algum tipo de curiosidade pelo assunto pesquisado. Os resultados revelam que $46 \%$ ( $9 \%$ nenhum e $37 \%$ pouco) perceberam que o curso não incentiva e/ou incentiva muito pouco o empreendedorismo entre os estudantes. Por outro lado, apenas $29 \%$ (19\% bastante e $10 \%$ totalmente) sentiram-se incentivados a serem empreendedores no decorrer do curso.

Quando se trata de ações empreendedoras por parte da universidade, 40\% (13\% nenhum e $27 \%$ pouco) diz que há pouca ou nenhuma atividade, projetos, cursos e grupos de discursões acerca do empreendedorismo na instituição, 35\% responderam razoável, e apenas 25\% (17\% bastante e $8 \%$ pouco), acreditam existir ações empreendedoras na universidade, indicando que a instituição tem que impulsionar mais o empreendedorismo dentro da organização.

Quanto a importância do empreendedorismo para a administração, a esmagadora maioria com 88\% (30\% bastante e 58\% total) reconhece a importância do empreendedorismo na administração, $6 \%$ razoável e apenas $6 \%$ (1\% nenhuma e 5\% pouca) acredita que há pouca ou nenhuma importância do empreendedorismo para a Administração. 53\% dos entrevistados (32\% bastante e $21 \%$ total) tem o empreendedorismo como prioridade na vida profissional, $29 \%$ razoável, e $18 \%$ (5\% nenhuma e $13 \%$ pouca) não tem o empreendedorismo como prioridade na vida profissional.

Tabela 2 - Avaliação sobre o Empreendedorismo

\begin{tabular}{c|c|c|c|c|c}
\hline Critérios & Nenhum & Pouco & Razoável & Bastante & Total \\
\hline Grau de interesse pelo empreendedorismo & $9 \%$ & $14 \%$ & $23 \%$ & $25 \%$ & $29 \%$ \\
\hline Incentivo do curso ao empreendedorismo & $9 \%$ & $37 \%$ & $25 \%$ & $19 \%$ & $10 \%$ \\
\hline $\begin{array}{c}\text { Ações empreendedoras (atividades, cursos, } \\
\text { projetos, grupos de discursões) }\end{array}$ & $13 \%$ & $27 \%$ & $35 \%$ & $17 \%$ & $8 \%$ \\
\hline $\begin{array}{c}\text { Importância do empreendedorismo para } \\
\text { administração }\end{array}$ & $1 \%$ & $5 \%$ & $6 \%$ & $30 \%$ & $58 \%$ \\
\hline $\begin{array}{c}\text { Empreendedorismo como prioridade na } \\
\text { vida profissional }\end{array}$ & $5 \%$ & $13 \%$ & $29 \%$ & $32 \%$ & $21 \%$ \\
\hline
\end{tabular}

Fonte: Elaborado pelos autores

Quando se trata dos perfis empreendedores que os Entrevistados mais se identificam, 54\% se consideram cautelosos (investem pouco e evitam assumir riscos) e $46 \%$ se consideram 
visionários (dispostos a assumir riscos e inovadores), mostrando equilíbrio nos dois perfis abordados na pesquisa, porém com um percentual maior para o perfil cauteloso.

Quanto aos pontos mais marcantes para ser empreendedor, onde poderia escolher 3 opções, a Tabela 3 mostra que $84 \%$ dos Entrevistados afirmam que inovação é a maior característica do empreendedor, segundo Dornelas (2007), todos os empreendedores tem um espirito em comum: o da inovação, peça central que transforma um empresário/administrador em empreendedor.

Dos entrevistados, 55\% acha que seja assumir riscos calculados, entendendo que para se arriscar deve ser feito um estudo/ planejamento acerca do negócio para que tenha o menor percentual de erro possível, assim chegando na obtenção do sucesso; e $40 \%$ acreditam ser auto confiança, pois um empreendedor visionário tem que acreditar em sua capacidade de realização, ter disciplina e foco para a auferir seus resultados, os três pontos mais marcantes para ser empreendedor.

Os demais pontos seguiram da seguinte forma: $33 \%$ realização e implementação de visões; agente de mudanças e estimulador no crescimento econômico ambos com 15\%, oportunista com $14 \%$, trabalhador eficiente (custo mínimo ) e multifuncional com 13\% cada, inventor $7 \%$, fundador da empresa e inaugurador de novos negócios ambos com 4\%, e empregador com apenas $1 \%$ dos resultados.

Tabela 3 - Prioridades para ser empreendedor

\begin{tabular}{l|l} 
Inovação & $84 \%$ \\
\hline Assumir riscos calculados & $55 \%$ \\
\hline Realização e implementação de visões & $33 \%$ \\
\hline Auto confiança & $40 \%$ \\
\hline Agente de mudanças & $15 \%$ \\
\hline Estimulador no crescimento econômico & $15 \%$ \\
\hline Oportunista & $14 \%$ \\
\hline Trabalhador eficiente (custo mínimo) & $13 \%$ \\
\hline Multifuncional & $13 \%$ \\
\hline Empregador & $1 \%$ \\
\hline Inventor & $7 \%$ \\
\hline Fundador da empresa & $4 \%$ \\
\hline Inaugurador de novos negócios & $4 \%$
\end{tabular}

Fonte: Elaborado pelos autores 
Em relação aos que pretendem empreender, 37,2\% dos alunos/egressos tem um emprego fixo, mas tem o empreendedorismo como uma renda extra, para complementar a renda mensal, $31,4 \%$ tem ou teve várias oportunidades de trabalho, porém quer empreender por sonhar com isso e $31,4 \%$ buscam empreender pelo fato de não conseguir se colocar no mercado de trabalho, vendo a sua única saída empreender.

Quando foi questionado por qual motivo não empreender, 45\% dos entrevistados se interessam por outra área da administração, 30,5\% dizem que não tem dinheiro para empreender, e 23,7\% não empreendem por medo de arriscar, evitam assim assumir riscos que possam comprometer seu investimento financeiro, buscando outras formas/áreas para adentrar no mercado de trabalho, recorrendo a concursos públicos, iniciativa privada, e demais áreas da Administração.

Observa-se que 68,6\% dos pesquisados tem tendência a serem empreendedores por oportunidade e apenas $31,4 \%$ empreendedores por necessidade. Os dados analisados revelam que $77 \%$ apresentam curiosidade pelo assunto pesquisado, porém sua maioria busca outras áreas da administração para difundir seu lado profissional.

A maioria se considera cauteloso na hora de empreender, investem pouco e evitam assumir riscos que possam comprometer suas finanças. Já quando o assunto é empreendedorismo por oportunidade e necessidade, os resultados são bastante positivos, para cada 1,6 alunos/egressos por necessidades, 3,4 são por oportunidade.

\section{Conclusão}

Os resultados mostram que, os alunos e egressos tem uma certa curiosidade acerca do empreendedorismo, porém apenas uma pequena parcela pensa em realmente montar seu próprio negócio, e viver do empreendedorismo, não tendo o incentivo necessário da universidade. Em sua maioria se consideram cautelosos, investem pouco e evitam assumir riscos, mas empreendem por oportunidade e não por necessidade, indicadores positivos na hora de montar um negócio.

A pesquisa contribui para o meio acadêmico por se tratar de um tema bastante debatido na atualidade e por fazer parte da grade do curso de administração, sendo o público alvo os estudantes e egressos de uma instituição de ensino superior, mostrando os impactos que o meio acadêmico traz nas escolhas dos seus alunos acerca do mercado de trabalho. Além disso, 
sua contribuição à sociedade, que vem a ser beneficiada pelos resultados positivos do empreendedorismo, como o aumento de postos de trabalho e da competitividade, fazendo com que a população tenha mais oportunidades para adentrar no mercado e ter mais opções de compras e serviços.

O trabalho traz possibilidades para novas pesquisas, por se tratar de um tema bastante recorrente, podendo fazer um paralelo com futuros estudantes e egressos em uma nova perspectiva, mostrando a evolução do empreendedorismo dentro da universidade.

Os discentes e docentes podem utilizar os resultados desse estudo para implementarem a cultura empreendedora na instituição, para quem sabe despertar o interesse dos alunos acerca do tema, pois é de bastante relevância para a sociedade que venha a usufruir dos benefícios causados pelo empreendedorismo, que nesse cenário de crise, seria uma forma de diminuir os impactos negativos que nossa região vem sofrendo, com a falta de emprego, dando a oportunidade a essas pessoas se integrarem ao mercado de trabalho.

\section{Referências}

DORNELAS, José Carlos Assis. Empreendedorismo na prática: Mitos e verdades do empreendedor de sucesso. $7^{\mathrm{a}}$ ed. São Paulo: Elsevier, 136 p, 2007.

BARROS, Aidil Jesus da Silveira; LEHFELD, Neide Aparecida de Jesus. Fundamentos de Metodologia Científica. 3. ed. São Paulo: Pearson, 2007.

BONA, André. Empreender por oportunidade ou necessidade? Acesso em 26 de novembro de 2019. Disponível em: https://andrebona.com.br/empreender-por-oportunidade-ou-necessidade/

CERBASI, Gustavo. Empreendedores inteligentes enriquecem mais: Inteligência financeira para quem já tem ou quer começar o próprio negócio. São Paulo: Sextante, 208 p, 2016.

CHÉR, Rogério. Nasce um Empreendedor: Empreendedores, empresários e executivos. In:

NUCCIO, Dony de; WOLLHEIM, Bob. Nasce um empreendedor: Dicas, provocação e reflexões para quem quer começar um negócio próprio. São Paulo: Portifolio Penguin, 2016. Cap. 1. p. 22-36.

CHIAVENATO, Idalberto. EMPREENDEDORISMO: DANDO ASAS AO ESPÍRITO EMPREENDEDOR. 4. ed. Barueri/sp: Manole, 315 p, 2012.

COSTA, Sandra Trujillo. Necessidade $\mathbf{X}$ oportunidade: o que muda no empreendedorismo com a crise. 2017. Acesso em 01 de abril de 2019). Disponível em: https://comunidadesebrae.com.br/blog/necessidade-xoportunidade-o-que-muda-no-empreendedorismo-com-a-crise.

CRESWELL, John W. Projeto de Pesquisa: Métodos e Qualitativos, Quantitativos e Mistos. 3. ed. São Paulo : Artmed, 2010. $296 \mathrm{p}$. 
CUSTODIO, Telma Padilha. A importância do empreendedorismo como estratégia de negócio. GuaiçaraSão Paulo, 2011. 62 p.

DORNELAS, José Carlos Assis. Empreendedorismo na prática: Mitos e verdades do empreendedor de sucesso. 7. ed. São Paulo: Elsevier, 136 p,2007.

DRUCKER, Peter Ferdinand. Inovação e Espírito Empreendedor: Prática e Princípios. 2. ed. São Paulo: Cengage Learning, 1986. 378 p. Tradução de Carlos J. Malferrari.

GEM- Global Entrepreneurship Monitor- Relatório Executivo ano 2017 Empreendedorismo no Brasil. Acesso em 15 de Outubro de 2018. Disponível em:https://m.sebrae.com.br/Sebrae/Portal\%20Sebrae/Anexos/Relat\%C3\%B3rio\%20Executivo\%20BRASIL_we b.pdf.

GEM- Global Entrepreneurship Monitor- Relatório Executivo ano 2018 Empreendedorismo no Brasil. Acesso em 28 de Abril de 2019. Disponível em: https://datasebrae.com.br/wpcontent/uploads/2019/02/Relat\%C3\%B3rio-Executivo-Brasil-2018-v3-web.pdf.

GIL, Antonio Carlos. Como Elaborar Projetos de Pesquisa. São Paulo: Atlas, 175 p, 2002.

HASHIMOTO, Marcos. A diferença entre ter uma empresa e ser empreendedor. 2016. Acessado em 05 de março de 2018, Disponível em: https://revistapegn.globo.com/Colunistas/Marcos-

Hashimoto/noticia/2016/09/diferenca-entre-ter-uma-empresa-e-ser-empreendedor.html

IBGE- Instituto Brasileiro de Geografia e Estatística 2018. Cidade Salgueiro/PE. Acesso em 05 de maio de 2019. Disponível em: https://www.ibge.gov.br/cidades-e-estados/pe/salgueiro.html.

MALLMANN, Tuani. (Novembro de 2017) Empreendedor por oportunidade e necessidade: entenda a diferença. Acesso em 28 de Março de 2019). Disponível em: https://coworkingbrasil.org/news/empreendedorpor-necessidade-ou-por-oportunidade/.

MAXIMIANO, Antonio Cesár Amaru. Empreendedorismo. In: MAXIMIANO, Antonio Cesár Amaru. Teoria Geral da Administração. 2. ed. São Paulo: Atlas, Cap. 20. p. 327-340. 2012.

MENDES, Jerônimo. Empreendedorismo 360º : A prática na prática. 3. ed. São Paulo: Atlas, 320 p. 2017.

NUCCIO, Dony de; WOLLHEIM, Bob. Nasce um empreendedor: Dicas, provocação e reflexões para quem quer começar um negócio próprio. São Paulo: Portifolio Penguin, p. 184,2016.

ODA, Luciana Sayuri. EMPREENDEDORISMO E INOVAÇÃO: A moeda para o sucessos nos negócios. 10 de Outubro de 2017. Disponível em Sebrae: https://blog.sebrae-sc.com.br/empreendedorismo-e-inovacao/. Acesso em 15 de abril de 2019.

PACHECO, Andressa Sasaki Vasques; NETO, Luis Moretto. A contribuição do curso de Administração da Universidade de Santa Catarina para o desenvolvimento de competências empreendedoras. Florianópolis, p.24. 2006. 
VALE, Glaucia Maria Vasconcelos; CORRÊA, Victor Silva; REIS, Renato Francisco dos. Motivação para o Empreendedorismo: Necessidade Versus Oportunidade. Rio de Janeiro 2014. 17 p.

VERGARA, Sylvia Constant. Métodos de Pesquisa em Administração. 6. ed. São Paulo: Atlas, 2015. 296 p. 